\title{
AN INVESTIGATION INTO NEIGHBORHOOD RESIDENTS' COGNITION OF AND PARTICIPATION IN LOW-CARBON BEHAVIOR: A CASE STUDY IN CHENGYANG DISTRICT OF QINGDAO, CHINA
}

\author{
W.J. PENG, X.M. WANG, G.C. ZHAO \& X. WANG \\ School of Civil Engineering and Mechanics, Huazhong University of Science and Technology, \\ Wuhan 430074, China.
}

\begin{abstract}
To discover potential approaches for meeting increasingly stringent emission controls, a questionnaire was launched in a newly built gated neighborhood in Chengyang district of Qingdao, China, to examine individual residents' cognition of and participation in low-carbon behaviors, which play a pivotal role in the construction of low-carbon neighborhoods. Statistical analysis of the questionnaires indicated that resident individuals' cognition regarding the paths to low-carbon neighborhood construction still centered on the traditional aspects of energy saving and emission reduction. The popularization of low-carbon lifestyles in all areas, such as "adoption of central cooling system" and "acceptance of laddering electricity price", in which potential low-carbon behaviors lie, is still an important mission of low-carbon transition in the near future. Furthermore, due to the relatively high level of local economic development and good traffic conditions in the surveyed neighborhood, a high proportion of residents were engaged in low-carbon behaviors from the perspective of transportation, such as "public transportation", "public bicycles or electromobiles" and "walking". Thus, to date, local residents have achieved good results in low-carbon mobility. The use of energy-efficient cars is also a potential field for emission reduction. Finally, suggestions were proposed to encourage residents' participation in low-carbon behaviors.

Keywords: cognition, low-carbon, neighborhood, participation, resident.
\end{abstract}

\section{INTRODUCTION}

\subsection{The enormous challenges of global warming facing humanity}

Global warming is one of the most urgent problems facing humanity today. The increasingly cumulative effects of global greenhouse gases have led to fragile environmental conditions, which threaten social and economic stability and human health. The United Nations Intergovernmental Panel on Climate Change (IPCC) has suggested that the increase in atmospheric $\mathrm{CO}_{2}$ concentration should be controlled to no more than twice the pre-industrial level $(560 \mathrm{ppm})$, and the rise in global average temperature to no more than the " $2{ }^{\circ} \mathrm{C}$ Threshold" to address climate change [1]. Therefore, a series of positive actions regarding a low-carbon economy must be taken by the international community. However, with rapid urbanization and modernization, the increase in energy consumption and carbon emissions continually imposes serious impacts on climate. For example, Chinese total energy consumption and per capita carbon emissions both rose sharply during 1996-2012 (Fig. 1). Moreover, urban areas contribute approximately $75 \%$ of global carbon emissions [2]. Hence, as the centre of social and technological innovations, urban areas are responsible for low-carbon transition. 


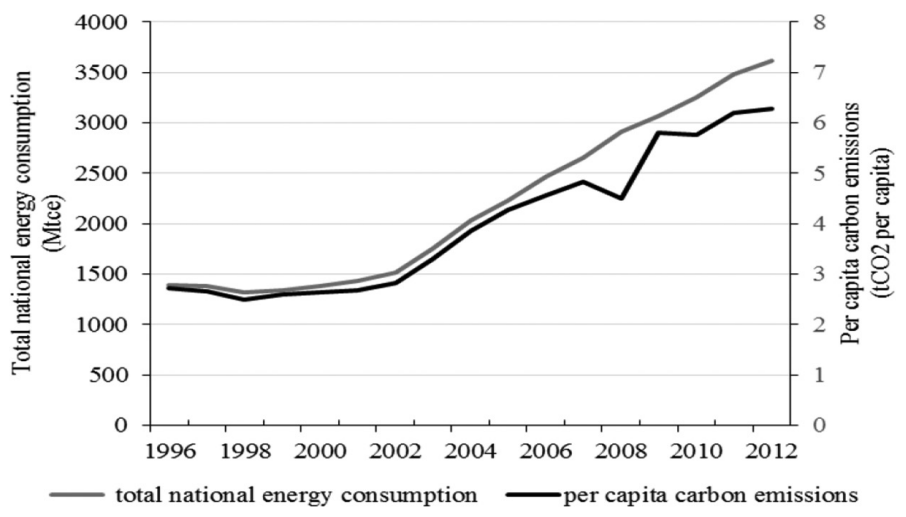

Figure 1: The trend of total energy consumption and per capita carbon emissions in China (Source: China Statistical Yearbook, 2013)

\subsection{Individual neighborhood residents' cognition of low-carbon behavior}

The human way of life is more and more influenced and inhibited by climate warming. To achieve sustainable development modes, it is necessary to find a balance between the environmental protection and the economic growth. As the basic building blocks of energy and resource consumption in cities, neighborhoods must undertake the important responsibility of reducing carbon emissions in order to address climate change and play an important role in applying the low-carbon concept to create low-carbon cities for sustainable development. Neighborhoods in this paper are defined as relatively independent human habitations, of different-sized populations, which are formed by urban roads or natural boundaries and supplemented by a certain scale of shared facilities to meet residents' living needs, recreation, daily material and cultural life [3,4]. Moreover, the majority of definitions of neighborhoods stress a place-based identity and uniform political and administrative power $[4,5]$.

In the context of the inevitable option of a low-carbon economy for the whole world in the century of global warming [6-8], the concept of the low-carbon neighborhood is put forward to promote the low-carbon transformation of cities as a new mode of neighborhood development [9-12]. Considering the many similarities and comparisons between neighborhoods and communities [4], in this paper, the low-carbon neighborhood is further particularly defined, referring to the relatively mature concept of a low-carbon community [13, 14]. Thus, 'low-carbon neighborhood' means a form of development to reduce the carbon-emission intensity of energy or resource consumption in residents' lifestyles and to increase renewable energy by setting up duties and mechanisms to encourage low-carbon related behaviors through residents' cooperation and collaboration. Furthermore, the 'construction of low-carbon neighborhoods' refers to the reduction in neighborhoods' greenhouse gas emissions from different aspects, including the use of energy and resources, transportation, land utilization types and energy conservation of buildings $[15,16]$. Up to now, many cities, such as London, Freiburg, Beder, Nagoya, Tianjin, Shenzhen and Shanghai, have proposed low-carbon objectives and low-carbon planning [17-22] to encourage the transition from traditional high-carbon development modes to low-carbon development modes in neighborhoods. Above all, against a background of rapid urbanization and industrialization, the choice of low-carbon neighborhood construction for carbon-emission reduction and to ease tensions between resources and environment is inevitable. 
Residents are behavioral agents, performing various activities in neighborhoods. In recent years, some authorities have carried out a series of empirical studies into people's low-carbon awareness and their actual behaviors and found a low-carbon awareness-behaviors gap in implementing low-carbon transformation [23, 24]. Furthermore, some papers have elaborated that low-carbon related awareness contributes to an improvement in people's participation in low-carbon behaviors [7, 25-27]. Specifically, Ueno et al. (2006) [28] stated that household members' energy-saving awareness influenced their daily power consumption of household appliances during standby or operation. Yu et al. (2011) [29] revealed that the attributes of household members influenced the energy consumption of appliances and vehicles. Zhu et al. [30] analyzed residents' cognition on the low-carbon concept, behaviors and participation willingness in urban districts. Hori et al. [25] surveyed the impact of social interaction, environmentally friendly behavior and global warming consciousness on energyconservation behaviors. Han et al. [31] explored factors including knowledge and intention, as well as circumstances that significantly affect energy-efficient behaviors. Yue et al. [32] empirically analyzed households' willingness to adopt different types of energy-efficient behaviors; these are influenced by socio-demographic attributes, energy-conservation awareness, behavioral ability and scenarios. Aldred and Jungnickel [33] discussed the impact of the cultural meanings of cycling, in relation to materials and competences, on cycling practices in urban areas. As discussed above, most of the previous literature has stressed the need to facilitate residents' low-carbon awareness and action-related skills and has put forward low-carbon related awareness from the aspects of personal knowledge, representation and attitude towards low-carbon objects, such as low-carbon concept, low-carbon related knowledge or global warming. Few authors, however, defined the concept of low-carbon cognition clearly before Bai and Liu [23], who defined low-carbon awareness as the status or quality of value, attitude and knowledge concerning the issue of cutting carbon dioxide emissions.

Almost at the same time, a growing body of literature carried out studies about low-carbon behaviors from residents' lifestyles and consumption patterns, which are closely related to energy conservation and carbon reduction in neighborhoods [34, 35]. Different solutions for decreasing the carbon intensity of citizens' lifestyles are evident from individual behavioral change [13]. For example, Ouyang and Hokao [36] proved that the improvement of occupants' energy-conservation behaviors in their domestic life contributed to household electricity saving. Fan et al. [37] divided end-use activities related to residential energy consumption into five categories, including lighting, heating and cooling, cooking and water heating, household appliances and personal transportation. Capstick et al. [38] explored feasible methods for individuals and households to radically reduce carbon dioxide emissions. In surveying the policy challenge facing China's government, Andrews-Speed and Ma [24] discovered the variability of household energy-saving behaviors.

However, as evident from the above review, few studies researched residents' cognition on low-carbon behaviors or measures. However, because, to date, implicit assumptions seriously inhibit low-carbon actions [38] or residential behaviors do not succeed in changing to the extent required [24], alternative approaches and fields need to be explored for energy conservation and emission reduction to improve the environment. Research into people's cognition on low-carbon paths is conducive to discovering potential areas for people to participate in low-carbon construction in their daily life. This paper tries to fill this gap and survey residents' cognition on low-carbon measures or behaviors to find out potential fields, as well as ways, for residents to reduce carbon emissions and energy consumption. Moreover, the concept of cognition of low-carbon behavior in this paper is regarded as neighborhood residents' 
knowledge about low-carbon measures or behaviors in their daily life for low-carbon neighborhood construction.

\subsection{Importance of resident participation in low-carbon neighborhood construction}

The sustainable development of urban communities needs diverse coordinated support, based on multiple objectives and demands to synchronously improve the physical environment and people's perception and behaviors [39-41]; and the same applies to urban neighborhoods, which are usually considered by social geographers as fundamental elements to create urban communities [42]. According to past progress and practices, low-carbon neighborhood construction specifically requires policy support from the government, basic protection of low-carbon technologies and the broad participation of residents [43-45]. Furthermore, compared with the other two requirement, resident participation is identified as playing an even more crucial role in promoting the construction of low-carbon neighborhoods, firstly, because it influences the decision-making processes and the implementation effect of low-carbon related policies and technologies [46] and, secondly, because the low-carbon transition of residents' lifestyles contributes to the formation of benign interactions among the economy, society, culture, politics and ecology [47, 48]. Therefore, resident participation provides an effective path to engage people individually or en masse in establishing low-carbon neighborhoods. Moreover, either the enhancement of a low-carbon life philosophy or the feasibility popularization of low-carbon lifestyles cannot be separated from resident participation.

Resident participation in low-carbon neighborhood construction means mobilizing an individual and collective intention of energy conservation and carbon dioxide reduction for a prosperous low-carbon economy. Resident participation is an important strategy for the transformation to a low-carbon neighborhood from a traditional high-carbon mode. Within their daily consumption patterns and lifestyles, there are many ways for neighborhood residents to participate in low-carbon transition. Residents' traditional lifestyle paths can be converted to low-carbon forms in their dietary behaviors, clothing consumption behavior and transportation [49]. Indicators including natural gas penetration, energy efficiency of household appliances, green travel ratio and the proportion of new energy vehicles together reflect residents' participation in low-carbon activities.

Because residents' daily mobility has become more and more significant for the sustainability of urban transport, low-carbon mobility is considered to be representative among numerous modes of resident participation in low-carbon behaviors. To date, a series of papers have analyzed residents' low-carbon mobility. For example, Banister [50] suggested that flexible paradigm and policy measures are available to realize sustainable mobility, especially in transport. Russo and Boutueil [51] thought that technological advances, as well as behavioral and organizational changes, support the transition to low-carbon transport. Prabhu and Pai [52] elaborated that the promotion of public transport bus services is an important strategy for reducing urban transport carbon dioxide emissions in Indian cities. Salonen et al. [53] emphasized the choices of suburban residents' daily mobility modes and proved that the respondents from a metropolitan area in Finland chose considerably more sustainable daily trip practices, such as walking, public transportation and cycling, rather than car travel. Mendoza et al. [54] demonstrated the potential to facilitate environmentally friendly mobility, such as e-bike and pedestrian, with the help of eco-products. Moreover, some authorities explored low-carbon mobility policies to encourage voluntary travel-behavior change towards low-carbon transport alternatives from highly car-dependent and carbon-intensive patterns [55, 56]. In sum, 
there is a need for research into neighborhood residents' participation in low-carbon daily mobility, in urban areas in particular, to support the appropriate development of local transport systems.

\subsection{Aim of this study}

Low-carbon neighborhood construction is important for the development of a low-carbon economy and low-carbon society. A questionnaire was launched in a neighborhood located in Chengyang District of Qingdao, China. The aim of the survey is to investigate resident individuals' cognition on low-carbon measures or behaviors in their daily life and their status and willingness regarding participation in low-carbon mobility. Furthermore, alternative new approaches for residents to make contributions to cutting carbon emissions in neighborhoods were discovered. Finally, suggestions were put forward to improve resident individuals' participation in low-carbon related activities in their daily life.

\section{MATERIAL AND METHODS}

Since 1994, the Administrative Centre for China's Agenda 21 has constructed over 190 China National Sustainable Communities in 146 cities to promote sustainable development. Representative of these is Chengyang district in Qingdao, China, which has simultaneously been awarded the status of "national ecological demonstration area" and "national green well-off county". It has a population of 737.2 thousand and covers an area of $553.2 \mathrm{~km}^{2}$. The coastal area of Chengyang district has geographic advantages for the use of new energy, including tidal, solar and wind energy. Low-carbon construction in Chengyang district is a typical pattern for the low-carbon transformation of new urban districts which have convenient transportation, modest housing prices, policy support and excellent environments to attract great numbers of people to settle there. Residents' cognition of and participation in low-carbon neighborhood construction is worth exploring to improve their cohesion and sense of belonging in respect of carrying out low-carbon behaviors.

The gated neighborhood selected in Chengyang district was built in 2011 and covers an area of $18112 \mathrm{~m}^{2}$, with plenty of public space for residents to interact. It is composed of six residential buildings and comprises about 2000 residents and 927 households. Though it is located in a newly developed area, it is surrounded by supporting facilities, such as hospitals, schools, shopping malls, theaters, banks and railway stations, for public services. Due to its convenient transportation, modest housing prices and excellent environments, the newlybuilt neighborhood attracted many immigrants from rural areas to settle here. In addition, its neighborhood committee often organizes a series of low-carbon educational activities to respond to urban development's requirement for low-carbon transformation. Thus, the investigation into neighborhood residents' low-carbon cognition and participation in low-carbon mobility is meaningful for low-carbon transition in newly developed areas and is conducive to formulating policies and measures for the relevant authorities.

A questionnaire was designed with multiple-choice answers in combination with comments to investigate resident individuals' cognition of low-carbon measures or behaviors related to neighborhood construction and to comprehend their status and aspiration regarding participation in low-carbon mobility. The created questionnaire was validated previously in Jiangan district in Wuhan, China. The questions stem from part of our research program and previous papers. To make it easy to understand and answer, the questionnaire was divided into three sections (Table 1). Section A contained questions pertaining to socio-demographic 
Table 1 Questions designed for analysis by section

\begin{tabular}{|c|c|c|}
\hline Item & Questions & References \\
\hline $\begin{array}{l}\text { Section A: } \\
\text { Socio- } \\
\text { demographic } \\
\text { Attributes }\end{array}$ & $\begin{array}{l}\text { Q1. Your age? } \\
\text { Q2. Your education level? } \\
\text { Q3. Your type of work or study unit? }\end{array}$ & {$[31,32]$} \\
\hline $\begin{array}{l}\text { Section B: } \\
\text { Resident } \\
\text { Individuals' } \\
\text { Cognition }\end{array}$ & $\begin{array}{l}\text { Q4. Which measures do you think are significantly important } \\
\text { paths for the construction of low-carbon neighborhoods? } \\
\text { (Multi-choice) } \\
\text { Q5. Which measures or behaviors do you think are the most } \\
\text { effective for saving energy at home? (Multi-choice) } \\
\text { Q6. Which aspects do you think local government should } \\
\text { prioritize when taking measures for low-carbon neighborhood } \\
\text { construction? (Multi-choice) }\end{array}$ & {$[36,37,44]$} \\
\hline $\begin{array}{l}\text { Section C: } \\
\text { Resident } \\
\text { Individuals' } \\
\text { Participation }\end{array}$ & $\begin{array}{l}\text { Q7. Which mode of daily transportation do you choose? } \\
\text { Q8. Which engine displacement of private cars do you tend to } \\
\text { choose? } \\
\text { Q9. Do you have advice for reducing carbon emissions from } \\
\text { vehicles? }\end{array}$ & {$[52,54]$} \\
\hline
\end{tabular}

attributes, including responders' age, educational level and profession. Section B was designed to investigate resident individuals' cognition or understanding of low-carbon neighborhood construction. Section C was designed to survey residents' participation status and participation willingness in respect of low-carbon transportation. The external forms of lowcarbon neighborhood construction are incarnate from green travel transportation, energy conservation of residential living and low-carbon consumption [57]. Although residents' lowcarbon participation ways include many aspects, transportation was thought to be the most direct and effective measure to reduce carbon emissions in people's daily lives and to significantly reflect people's low-carbon behaviors. Thus, it was selected for the inquiry into individual residents' participation in low-carbon neighborhood construction. The survey contained nine questions, with three in each section. Among them, the first eight questions offered alternatives, while the last question was open-ended.

The investigation was carried out in public places for residents who lived in the neighborhood and were willing to be interviewed. The questionnaires were distributed during neighborhood residents' break times. To obtain representative population samples across variations and an adequate response rate, accidental sampling, associated with stratified random sampling, was adopted to collect samples. Meanwhile, the full range of residents' ages, educational levels and professions was covered as far as possible during the survey. During the data collection stage, the research objective and clear instructions on how the data were to be used were firstly explained to respondents. Moreover, respondents were well informed that their responses would remain confidential and only be used for research purposes. Then questionnaires were handed to each respondent directly, to be filled in under interviewers' attention. The survey process mainly contained self-administered questionnaires, supplemented by semi-structured interview methods, to complete each questionnaire. Meanwhile, self-administered semi-structured interviews with neighborhood residents helped researchers 
to discern their knowledge about low-carbon related ideas and give appropriate explanations as required. Each questionnaire took about 15 minutes to complete. The participants were followed up and received a small gift as a reward for filling out the questionnaires at the end. Finally, questionnaires were recovered directly from these interviewees.

In addition, EXCEL statistical software was used for the statistical analysis of the sample data. The descriptive data and categorical variables were both expressed as percentages. The comments advised by respondents were summarized point by point.

\section{RESULTS}

\subsection{Section A: characteristics of samples}

A total of 122 questionnaires were distributed and 122 were retrieved. After screening, four invalid questionnaires due to absent items were deducted, and 118 valid questionnaires were used for the research, with an effective return rate of $94.4 \%$. The ages of participants ranged from 17 to 56 years, with a mean of 27.42 and a standard deviation of 7.29 years. From the survey's distribution of socio-demographic characteristics (Table 2), the interviewees covered inhabitants of different ages, cultural levels and occupations in the neighborhood. According to the information provided by the neighborhood's property managers, the sample basically reflects the current status of residents. Thus, the neighborhood-based survey is representative enough to reflect the whole population living here. Furthermore, the basic statistical information about respondents was in line with our research demand, without greatly skewed distribution. Respondents' age distribution shows that the survey mainly collected samples under 29 years of age, accounting for $54 \%$ of the total. In the aspect of education, $53 \%$ of the respondents had a bachelor's degree or above. Respondents' good educational background is beneficial to local sustainable development. As for occupation, 35\% of respondents were enterprise employees. Interviewees who chose the option of "other" accounted for $30 \%$ of the total and were comprised chiefly of self-employed businessmen.

\subsection{Section B: low-carbon cognition}

Survey question 4 was used to collect data on residents' cognition of ways to carry out lowcarbon neighborhood construction. The statistical results are shown below (Fig. 2). "Energy

Table 2 Socio-demographic attributes of samples

\begin{tabular}{llllll}
\hline Age & Percentage & Educational level & Percentage & Occupation & Percentage \\
\hline$\leq 20$ years old & $16 \%$ & $\begin{array}{l}\text { Middle School or } \\
\text { Below }\end{array}$ & $15 \%$ & $\begin{array}{l}\text { Enterprise } \\
\text { Employee }\end{array}$ & $35 \%$ \\
21-29 years old & $38 \%$ & $\begin{array}{l}\text { High School or } \\
\text { Technical School }\end{array}$ & $32 \%$ & $\begin{array}{l}\text { Government } \\
\text { or Institution }\end{array}$ & $16 \%$ \\
& & College & $49 \%$ & $\begin{array}{l}\text { Employee } \\
\text { Student }\end{array}$ & $19 \%$ \\
$30-39$ years old & $28 \%$ & Graduate & $4 \%$ & Other & $30 \%$ \\
$40-49$ years old & $12 \%$ & Total & $100 \%$ & Total & $100 \%$ \\
$\geq 50$ years old & $6 \%$ & $100 \%$ & & &
\end{tabular}




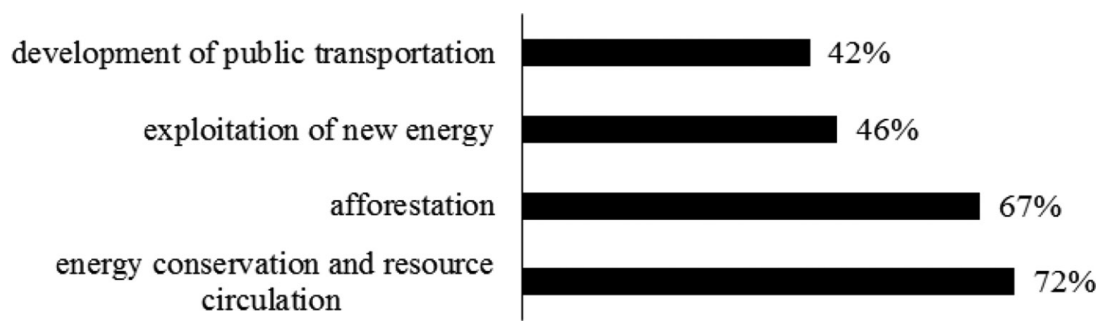

Figure 2: Paths for carrying out low-carbon construction in neighborhoods

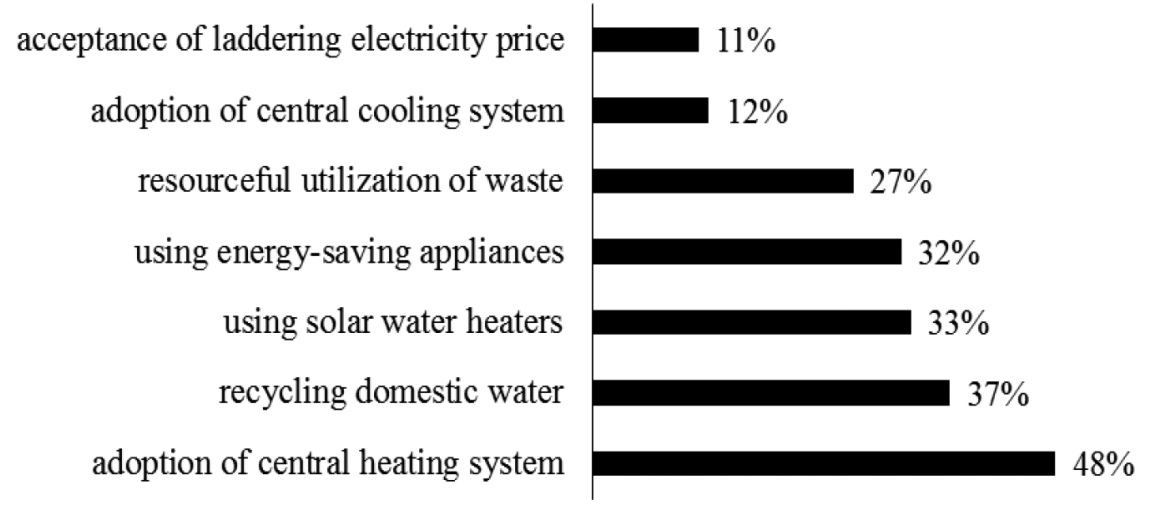

Figure 3: Cognition of energy-saving behaviors at home

conservation and resource circulation" were thought to be the most important paths for lowcarbon neighborhood construction by $72 \%$ of respondents, followed in turn by $67 \%$ for "afforestation", $46 \%$ for "exploitation of new energy" and $42 \%$ for "development of public transportation". Thus, over $40 \%$ of respondents had a certain amount of cognitive reserves about different low-carbon measures, which can be classified as carbon source control and carbon sinks expansion.

Survey question 5 was used to collect data on residents' cognition of energy-saving behaviors at home. The statistical results were achieved as follows (Fig. 3). Respondents' cognition on low-carbon behaviors in their daily life covers a wide range. These residents paid the greatest attention to residential central heating, which accounted for $48 \%$, followed in turn by domestic water recycling, the use of solar power, the use of energy-saving appliances and resourceful utilization of waste, accounting for $37 \%, 33 \%, 27 \%$ and $32 \%$, respectively. Meanwhile, the selected portions of "adoption of central cooling system" and "acceptance of laddering electricity price" are very small, accounting for $12 \%$ and $11 \%$, respectively. This shows that residents' cognition of measures in low-carbon neighborhood construction remain rooted in traditional aspects of energy conservation. Thus, there is a need to further strengthen related publicity and education.

Survey question 6 was used to collect data on the areas in which respondents expected local government to increase policy support and capital investment for the low-carbon development of neighborhoods. The statistical results are shown below (Fig. 4). Over half the people chose "greenland construction" (61\%) and "pollution control" (59\%), followed by "energy efficient buildings" (46\%), "public transportation" (43\%), and "construction of 


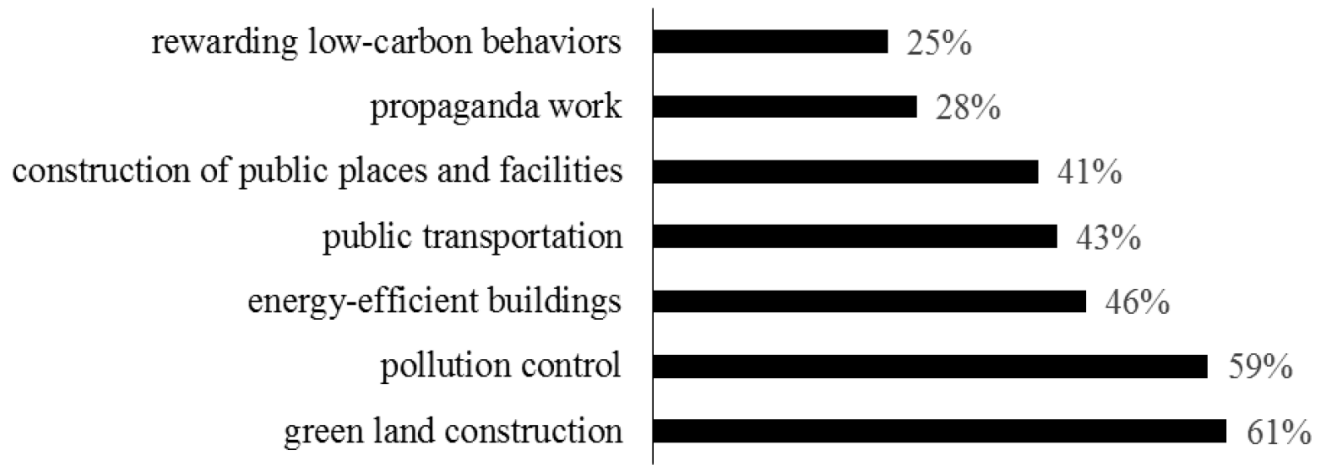

Figure 4: Different aspects for government to increase policy support and capital investment

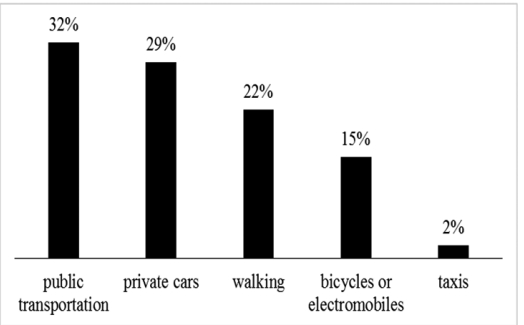

(a)

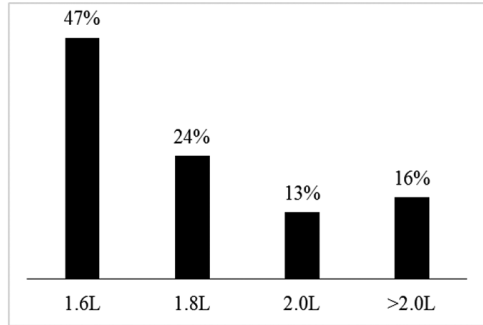

(b)

Figure 5: Statistical analysis of respondents' daily mobility: (a) mode choices (b) tendency to purchase private cars with engine displacement

public places and facilities" (41\%). Meanwhile, "propaganda work" and "rewarding lowcarbon behaviors" accounted for $28 \%$ and $25 \%$, respectively. Thus, residents want the government to improve different aspects of low-carbon development to guarantee their implementation conditions, especially in the field of greenland construction and pollution control.

\subsection{Section C: participation in low-carbon mobility}

Figure 5(a) shows the analyzed results of the respondents' traveling modes, based on Q7. The figure shows that $69 \%$ of respondents chose low-carbon traveling modes, which were constituted of public transportation (32\%), walking (22\%) and bicycles or electromobiles (15\%). The choice of private cars and taxis accounted for $29 \%$ and $2 \%$, respectively. While filling out survey question 8 , the resident individuals were first asked to answer whether they owned a car. Response categories contained "Yes" and "No". If the answer was "Yes", they were asked which car with engine displacement they owned. Then they were asked which car with engine displacement they would use if they could choose. If the answer was "No", they were asked directly which car with engine displacement they would choose. From the questionnaire survey conducted, $28 \%$ of respondents had their own cars. The other $72 \%$ of respondents did not own cars. The respondents who chose vehicles with less than or equal to 1.8-liter engines accounted for $64 \%$ of the respondents who owned cars. The statistical results of all 
respondents' purchase tendency of private cars with engine displacement can be integrated together for comparative analysis (Fig. 5b). The figure shows that most respondents preferred vehicles with low engine displacement, with $47 \%$ choosing 1.6-liter engines and $24 \%$ choosing 1.8-liter engines. But there are still $29 \%$ who chose vehicles with engine displacement equal to or more than 2.0 liter.

Finally, according to open-ended Question 9, advice put forward by respondents for reducing carbon emissions from vehicles were summarized as follows. (1) It is necessary to strictly control the number of private cars on the road to minimize tailpipe emissions which cause serious air pollution. (2) A preferential policy, such as lower fares and priority development of public transport, helps raise the frequency and proportion of traveling by public transit systems. (3) Vigorous promotion of energy-saving vehicles, accompanied by a big improvement in subsidies for public transportation, can help reduce carbon emissions. (4) Neighborhood residents can be encouraged to participate in low-carbon travel by increasing the number of bus stops, bike stations and railway facilities. More greenways also contribute to encouraging residents to drive cars less and walk more. (5) Preferential measures and services for cars with small engine displacement can draw residents away from a high tax for vehicles with high engine displacement to buy more environmentally friendly cars. (6) Strengthening education for residents is the primary task for improving residents' participation in low-carbon travel.

\section{DISCUSSION}

\subsection{Main findings}

The statistical analysis of the questionnaires reached the following conclusions.

1. The respondents had a relatively high-level cognition of low-carbon neighborhood construction, probably because more than half the respondents possessed a high-level educational background. Respondents realized that energy conservation, resource circulation and afforestation are highly conducive to low-carbon neighborhood construction. In their daily life, however, residents pay more attention to the adoption of home heating, water recycling, use of solar power and energy-saving appliances. The small proportions of those selecting "adoption of central cooling system" and "acceptance of laddering electricity price" indicated that residents' cognition of low-carbon behaviors is still rooted in traditional aspects of energy conservation. There is potential for residents to reduce carbon dioxide from domestic low-carbon behaviors. Besides further strengthening the related publicity and education, the improvement of the different aspects of low-carbon development by the local government will help to guarantee residents' implementation conditions, especially in the fields of green land construction and pollution control. In sum, the popularization of low-carbon lifestyles in all directions seems to be an important mission of low-carbon transition in the near future.

2. Most neighborhood residents participated in low-carbon transportation and realized that traffic carbon emission was the main cause of air pollution. Almost $70 \%$ of residents chose low-carbon travel, such as public transportation, walking and biking. About $50 \%$ of residents tended towards low-emission vehicles, which is likely to be a potential field for residents to participate in low-carbon behaviors. They also made some recommendations for improving the quality of the living environment, from the perspective of transporta- 
tion, in response to open-ended Q9, such as strict control of the number of private cars, encouraging walking, development of public transportation and promotion of energyefficient cars. The results showed the importance of good traffic conditions and local economic development level for people's active participation. In addition, many universities, such as Qingdao Agricultural University and Qingdao University of Technology in Chengyang district, often carried out low-carbon activities. Radiation of these activities would effectively promote the low-carbon development of their neighborhood and their surrounding neighborhoods. Moreover, these universities provide long-term power for neighborhoods' low-carbon transformation.

\subsection{Suggestions}

The transition of low-carbon lifestyles directly affects neighborhoods' original operation mode. Resident participation promotes the shifting of neighborhoods' paradigms from traditional high-carbon ones to low-carbon ones. The following suggestions are proposed to encourage individual residents' participation in low-carbon neighborhood construction, based on the existing literature and inspiration from the findings.

1. The enhancement of interactions among neighborhood residents helps facilitate resident participation in the low-carbon transition of neighborhoods, because flexible individual behaviors are very likely to expand opportunities for informal meetings or gatherings to accomplish one goal [58]. However, with China's modernization and urbanization, residents of different cultures and ethnicities gather and live in urban neighborhoods, especially those formed by high-rise residential buildings, which leads to a decrease in interactions and an increase in indifference among neighborhood residents [59, 60]. Moreover, lack of trust and cooperation among individuals affects residents' participation enthusiasm and effectiveness and hinders their autonomy in low-carbon neighborhood construction. Hence, interactions among neighborhood residents promote individual participation in behavioral change to low-carbon transition.

2. Public spaces, including residential landscaping and entertainment areas, are conducive to individual residents' participation in low-carbon neighborhood construction. On the one hand, residential landscaping in neighborhoods not only plays a vital role in increasing carbon sinks and reducing heat island effect [61, 62], but it also provides continuous and comfortable use for residents to stay longer [63]. That is to say, green space helps to extend residents' period of residence in one neighborhood, which is conductive to ultimately achieving the sustainable development. Moreover, some environmentalists initiate environmentally-friendly buildings for enjoying sustainable landscaping, which is preferred by eco-conscious consumers [64]. In brief, residents' participation in low-carbon neighborhood construction can be effectively advanced by sustainable utilization of green space. On the other hand, activity areas increase the possibility of engagement and interaction among neighborhood residents [63]. Furthermore, entertainment areas provide platforms for residents to learn and exchange experience or knowledge of low-carbon neighborhood construction.

3. The construction of low-carbon neighborhoods calls for residents to be empowered by increasing their involvement in decision-making about their own lives [65, 66]. The reconstruction of a bottom-up power structure stimulates individual residents' initiatives and ultimately contributes to achieving a self-governing and citizen-led governance mode 
[67]. The approach of empowering neighborhood residents helps them to develop organizational structures and aggregate public initiatives for participation, and to jointly discuss and create strategies for the environment [66, 68]. Residents' self-governance effectively promotes durable participation in low-carbon behaviors, as long-term residents in a neighborhood are relatively clear about how to use resources rationally and protect the ecological environment. Furthermore, self-education through resident brainstorming can best meet the population's needs and help to reduce carbon emission in neighborhoods. More specifically, participants can fully take into account the combination of a consensus, based on shared and private spaces such as kitchens, laundries, lawns and libraries, to design an autonomous neighborhood. In this way, household expenses can be reduced by energy saving and resource conservation. In sum, it is necessary to mobilize residents' low-carbon behaviors and encourage them to consciously practice low-carbon ideas in their daily lives.

4. It is necessary to consider policy and regulations in supporting resident participation in low-carbon neighborhood construction. In order to promote the implementation of green technologies and strategies in low-carbon development at the neighborhood level, policy innovation is demanded to incorporate new information and ensure the effectiveness of execution $[69,40]$. More than that, low-carbon oriented policies encourage residents' participation in low-carbon behaviors in their daily lives for a more sustainable environment $[3,70,9]$. Feasible administrative mechanisms enhance scientific decision-making for the low-carbon transition of neighborhoods [71]. Therefore, policy formulation is conducive to consolidating resident participation.

5. Non-governmental organizations help to facilitate resident individuals' participation in low-carbon neighborhood construction. With environmentalism or green living becoming a global movement, many organizations have been formed, based on this theory, to help govern people's living styles [72]. Firstly, these organizations have the advantage of being close to the grassroots to improve residents' awareness of sustainable development [73]. Meanwhile, they help neighborhoods establish incentive mechanisms in environmental protection to attract resident participation in low-carbon neighborhood construction. Secondly, due to their advantages of flexibility and adaptation, non-governmental organizations can adjust immediately, according to residents' advice, to deal with environmental issues and embody residents' values of participation initiatives [74]. Thus, it is necessary to emphasize the roles of non-governmental organizations in promoting individual participation in low-carbon neighborhood construction.

\subsection{Limitations}

The findings in this report are subject to several limitations. Firstly, a non-response bias could not be ruled out because participation in the study was voluntary and the residents who chose to answer the questionnaire may have been more concerned about other low-carbon behaviors than other residents. Secondly, using self-answered questionnaires possibly increases the proportion of dishonesty in the given answers. The data acquired is subjective. Thirdly, the study only considered traffic and travel but no other aspects related to low-carbon behaviors, such as usage patterns of domestic energy by dwelling. In addition, as a descriptive essay, the relationship between neighborhood residents' social-demographic characteristics, their cognition of low-carbon behaviors and their participation in low-carbon mobility is not discussed. 
However, statistical results depict the existing gap between the goal and the status of carbon reduction and may clarify the ways for advancing towards low-carbon neighborhood construction.

\section{CONCLUSIONS}

The empirical study carried out a questionnaire survey to investigate residents' cognition on low-carbon behaviors in low-carbon neighborhood construction and their status and willingness regarding participation in low-carbon mobility. The results showed that individual residents' cognition of measures for low-carbon neighborhood construction was still rooted in the traditional aspects of energy saving and emission reduction. Their behaviors showed interest-oriented modes. Thus, it is important to enhance the propaganda and education about low-carbon ideas. In the aspect of transportation, most residents are willing to practice lowcarbon mobility, possibly because of the relatively high economic development level and good traffic conditions in the newly developed urban neighborhood.

To achieve low-carbon styles in residents' attitudes to consumption and modes of travel in the future, it is necessary to improve low-carbon neighborhood construction from the technical, theoretical, organizational and institutional aspects. Resident participation in low-carbon behaviors contributes to low-carbon neighborhood construction. The mobilization of residents' enthusiasm for participation makes them voluntarily practice low-carbon lives. Neighborhood residents in the subject district did show potential for low-carbon behavior change in their daily life, such as central cooling and laddering electricity prices. Their involvement in low-carbon behaviors can be encouraged with guaranteed conditions. Overall, this paper is exploratory in nature and aims to identify potential fields of significant emissions' reduction that can be confirmed in later research.

\section{ACKNOWLEDGEMENTS}

The present study was approved by the Key Project of National Science and Technology Support Program for the Twelfth Five-Year Plan of China, "Research and Demonstration of Planning and Construction Monitoring Technology in Green Ecological Village" (2014BAL04B03-3).

\section{APPENDIX}

\begin{tabular}{lll}
\hline Note & Items & Options \\
\hline $1 \quad$ Your age? & $\circ \leq 20$ \\
& & $\circ 21-29$ \\
& $\circ 30-39$ \\
& $\circ 40-49$ \\
& $\circ \geq 50$ \\
& & $\circ$ Middle School or Below \\
& & $\circ$ High School or Technical School \\
& Your education level? & $\circ$ College \\
& & $\circ$ Graduate \\
& & $\circ$ Enterprise Employee \\
& & $\circ$ Government or Institution Employee \\
& & $\circ$ Student \\
& & $\circ$ Other \\
\hline
\end{tabular}




\begin{tabular}{|c|c|c|}
\hline Note & Items & Options \\
\hline 4 & $\begin{array}{l}\text { Which measures do you think constitute } \\
\text { significantly important paths for the con- } \\
\text { struction of low-carbon neighborhoods? } \\
\text { (Multi-choice) }\end{array}$ & $\begin{array}{l}\text { - Afforestation } \\
\circ \text { Exploitation of new energy } \\
\circ \text { Development of public transportation } \\
\circ \text { Energy conservation and resource } \\
\text { circulation }\end{array}$ \\
\hline 5 & $\begin{array}{l}\text { Which measures or behaviors do you } \\
\text { think are the most effective for saving } \\
\text { energy at home? (Multi-choice) }\end{array}$ & $\begin{array}{l}\text { O Adoption of central heating system } \\
\text { o Adoption of central cooling system } \\
\text { ○ Using energy-saving appliances } \\
\text { o Acceptance of laddering electricity } \\
\text { price } \\
\text { o Using solar water heaters } \\
\text { o Recycling domestic water } \\
\text { o Resourceful utilization of waste }\end{array}$ \\
\hline 6 & $\begin{array}{l}\text { Which aspects do you think local gov- } \\
\text { ernment should prioritize when taking } \\
\text { measures for low-carbon neighborhood } \\
\text { construction? (Multi-choice) }\end{array}$ & $\begin{array}{l}\circ \text { Pollution control } \\
\circ \text { Green land construction } \\
\circ \text { Public transportation } \\
\circ \text { Construction of public places and } \\
\text { facilities } \\
\circ \text { Propaganda work } \\
\circ \text { Rewarding low-carbon behaviors } \\
\circ \text { Energy-efficient buildings }\end{array}$ \\
\hline 7 & $\begin{array}{l}\text { Which is your main daily mode of trans- } \\
\text { portation? }\end{array}$ & $\begin{array}{l}\text { Walking } \\
\text { - Bicycles or electromobiles } \\
\text { Taxis } \\
\text { - Public transportation } \\
\text { - Private cars }\end{array}$ \\
\hline \multirow[t]{4}{*}{8} & Do you own a car? & $\circ$ Yes $\circ$ No \\
\hline & $\begin{array}{l}\text { 1. If yes, what is your car's engine dis- } \\
\text { placement? }\end{array}$ & $\circ 1.6 \mathrm{~L} \odot 1.8 \mathrm{~L} \odot 2.0 \mathrm{~L} \odot>2.0 \mathrm{~L}$ \\
\hline & $\begin{array}{l}\text { 2. Moreover, if you could choose, which } \\
\text { engine displacements of private cars } \\
\text { would you purchase? }\end{array}$ & $\circ 1.6 \mathrm{~L} \odot 1.8 \mathrm{~L} \odot 2.0 \mathrm{~L} \odot>2.0 \mathrm{~L}$ \\
\hline & $\begin{array}{l}\text { 3. If no, which engine displacements of } \\
\text { private cars would you tend to choose? }\end{array}$ & $\circ 1.6 \mathrm{~L} \circ 1.8 \mathrm{~L} \circ 2.0 \mathrm{~L} \circ>2.0 \mathrm{~L}$ \\
\hline 9 & Do you have advice for reducing carbon e & missions from vehicles? \\
\hline
\end{tabular}

\section{REFERENCES}

[1] IPCC. Climate change 2007: synthesis report. Contribution of working groups I, II and III to the Fourth Assessment Report of the Intergovernmental Panel on Climate Change, Geneva, Switzerland, 2007.

[2] Zhang, L.Y. The role of community action in low-carbon urban transitions in China and UK. In J. Zhou \& W. Zhu (Eds.), Community. Space. Governance: City \& Society International Forum 2015 Shanghai China Proceedings. Tongji University Press: Shanghai, 2015. 
[3] Basolo, V. \& Strong, D., Understanding the neighborhood: from residents' perceptions and needs to action. Housing Policy Debate, 13(1), pp. 83-105, 2002. https://doi.org/10.1080/10511482.2002.9521436

[4] Park, Y. \& Rogers, G.O., Neighborhood planning theory, guidelines, and research: can area, population, and boundary guide conceptual framing?. Journal of Planning Literature: Incorporating the CPL Bibliographies, 30(1), 1-19, 2015.

[5] Amidoleslam, S., Negar, H.S. \& Maryam, B.F., An analytical study on boundaries of administrative - defined neighborhoods using residents' cognitive maps (case study: Mashhad municipality neighborhoods, Iran). Optics Express, 18(6), pp. 5920-5925, 2014.

[6] Hong, W. (2011). Notice of retraction research on the corporate social responsibility performance index under the low carbon economy - from the case analysis of CNPC. International Conference on E - Business and E - Government. IEEE, pp. 1-5.

[7] Chen, H., Long, R., Niu, W., Feng, Q. \& Yang, R., How does individual low-carbon consumption behavior occur? - an analysis based on attitude process. Applied Energy, 116(5), pp. 376-386, 2014. https://doi.org/10.1016/j.apenergy.2013.11.027

[8] Hui, F., Overview of low-carbon economy research. Asian Journal of Agricultural Research, 2(12), pp. 65-69, 2010.

[9] Li, Z., Quan, S.J. \& Yang, P.J., Energy performance simulation for planning a low carbon neighborhood urban district: a case study in the city of Macau. Habitat International, 53, 206-214, 2016. https://doi.org/10.1016/j.habitatint.2015.11.010

[10] Chattopadhyay, S., Banerjee, S. \& Sen, R., Mapping low-carbon precincts in residential neighbourhoods: a comparative case study of the traditional and the modern types. Journal of Engineering Technology, 3(4), pp. 17-24, 2016.

[11] Mirzaei, H., Enhancing low carbon neighborhood through building rehabilitation in Kerman City of Iran. Johor: Universiti Teknologi Malaysia, 2014.

[12] Yang, T., Chen, H., Zhang, Y., Zhang, S. \& Feng, F., Towards low-carbon urban forms: a comparative study on energy efficiencies of residential neighborhoods in Chongming Eco-Island. Energy Procedia, 88, pp. 321-324, 2016. https://doi.org/10.1016/j.egypro.2016.06.142

[13] Heiskanen, E., Johnson, M., Robinson, S., Vadovics, E. \& Saastamoinen, M., Low-carbon communities as a context for individual behavioural change. Energy Policy, 38(12), pp. 7586-7595, 2010.

https://doi.org/10.1016/j.enpol.2009.07.002

[14] Moloney, S., The hidden potential of sustainable neighborhoods: lessons from lowcarbon communities. Urban Policy \& Research, 33, pp. 383-385, 2015. https://doi.org/10.1080/08111146.2015.1057913

[15] Qin, B. \& Shao, R., The impacts of urban form on household carbon emissions: a case study on neighborhoods. City Planning Review, 2012.

[16] Zhou, Y. \& Qian, C., Neighborhood functions and layout for low carbon transportation. Planners, 2014(9), pp. 82-87, 2014.

[17] Zhu, D., Kung, M. \& Zhou, L., Analysis of sustainable energy systems in ecovillages: a review of progress in BedZED and Masdar City. Low Carbon Economy, 6(1), pp. 1-6, 2015.

https://doi.org/10.4236/lce.2015.61001 
[18] Ye, W.H. \& Huang, R.Q., Shenzhen neighborhood planning from social management viewpoint. Planners, 29(5), pp. 76-80, 2013.

[19] Caprotti, F., Springer, C. \& Harmer, N., 'Eco' for whom? Envisioning eco-urbanism in the Sino-Singapore Tianjin Eco-city, China. International Journal of Urban and Regional Research, 39(3), pp. 495-517, 2015.

https://doi.org/10.1111/1468-2427.12233

[20] Murayama, A., Morita, H., Fujimori, M. \& Endoh, Y., The implementation of municipal low-carbon city strategy through community development in existing urban area: the current situation and issues of Nagoya city and Nishiki 2 low-carbon model district. Journal of the City Planning Institute of Japan, 51, 2016.

[21] Hamiduddin, I., Social sustainability, residential design and demographic balance: neighbourhood planning strategies in Freiburg, Germany. Town Planning Review, 86(1), pp. 29-52, 2015. https://doi.org/10.3828/tpr.2015.3

[22] Espinosa, A. \& Walker, J., Complexity management in practice: a viable system model intervention in an Irish eco-community. European Journal of Operational Research, 225(1), pp. 118-129, 2013.

https://doi.org/10.1016/j.ejor.2012.09.015

[23] Bai, Y. \& Liu, Y., An exploration of residents' low-carbon awareness and behavior in Tianjin, China. Energy Policy, 61, pp. 1261-1270, 2013. https://doi.org/10.1016/j.enpol.2013.06.014

[24] Andrews-Speed, P. \& Ma, G., Household energy saving in China: the challenge of changing behavior. In B. Su \& E. Thomson (Eds.), China's Energy Efficiency and Conservation. SpringerBriefs in Environment, Security, Development and Peace. Springer, Singapore, 2016.

[25] Hori, S., Kondo, K., Nogata, D. \& Ben H., The determinants of household energysaving behavior: survey and comparison in five major Asian cities. Energy Policy, 52(s3-4), pp. 354-362, 2013.

https://doi.org/10.1016/j.enpol.2012.09.043

[26] Vassileva, I. \& Campillo, J., Increasing energy efficiency in low-income households through targeting awareness and behavioral change. Renewable Energy, 67(7), pp. 5963, 2014.

https://doi.org/10.1016/j.renene.2013.11.046

[27] Wang, S., Fan, J., Zhao, D., Yang, S. \& Fu, Y., Predicting consumers' intention to adopt hybrid electric vehicles: using an extended version of the theory of planned behavior model. Transportation, 43(1), pp. 123-143, 2016.

https://doi.org/10.1007/s11116-014-9567-9

[28] Ueno, T., Sano, F., Saeki, O. \& Tsuji, K., Effectiveness of an energy-consumption information system on energy savings in residential houses based on monitored data. Applied Energy, 83(2), pp. 166-183, 2006. https://doi.org/10.1016/j.apenergy.2005.02.002

[29] Yu, B., Zhang, J. \& Fujiwara, A., Representing in-home and out-of-home energy consumption behavior in Beijing. Energy Policy, 39(7), pp. 4168-4177, 2011. https://doi.org/10.1016/j.enpol.2011.04.024

[30] Zhu, L., Lin, F. \& Lu, H., Status quo of residents' low-carbon life in Minhang district: survey and enlightenment. Environmental Science \& Technology, 35(1), pp. 195-200, 2012. 
[31] Han, Q., Nieuwenhijsen, I., Vries, B.D., Blokhuis, E. \& Schaefer, W., Intervention strategy to stimulate energy-saving behavior of local residents. Energy Policy, 52, pp. 706-715, 2013. https://doi.org/10.1016/j.enpol.2012.10.031

[32] Yue, T., Long, R. \& Chen, H., Factors influencing energy-saving behavior of urban households in Jiangsu Province. Energy Policy, 62(9), pp. 665-675, 2013. https://doi.org/10.1016/j.enpol.2013.07.051

[33] Aldred, R. \& Jungnickel, K., Why culture matters for transport policy: the case of cycling in the UK. Journal of Transport Geography, 34(219), pp. 78-87, 2014. https://doi.org/10.1016/j.jtrangeo.2013.11.004

[34] Lopes, L., Hokoi, S., Miura, H. \& Shuhei, K., Energy efficiency and energy savings in Japanese residential buildings - research methodology and surveyed results. Energy and Buildings, 37(7), pp. 698-706, 2005. https://doi.org/10.1016/j.enbuild.2004.09.019

[35] Heijs, W., Household energy consumption. In W. Heijs (Ed.), Household Energy Consumption. Habitual Behavior and Technology, Springer, 2006.

[36] Ouyang, J. \& Hokao, K., Energy-saving potential by improving occupants' behavior in urban residential sector in Hangzhou City, China. Energy \& Buildings, 41(7), pp. 711-720, 2009. https://doi.org/10.1016/j.enbuild.2009.02.003

[37] Fan, J.L., Liao, H., Liang, Q.M., Tatano, H., Liu, C.F. \& Wei, Y.M., Residential carbon emission evolutions in urban-rural divided China: an end-use and behavior analysis. Applied Energy, 101(1), pp. 323-332, 2013. https://doi.org/10.1016/j.apenergy.2012.01.020

[38] Capstick, S., Lorenzoni, I., Corner, A. \& Whitmarsh, L., Prospects for radical emissions reduction through behavior and lifestyle change. Carbon Management, 5(4), pp. 429-445, 2015. https://doi.org/10.1080/17583004.2015.1020011

[39] Torvanger, A. \& Meadowcroft, J., The political economy of technology support: making decisions about carbon capture and storage and low carbon energy technologies. Global Environmental Change, 21(2), pp. 303-312, 2011. https://doi.org/10.1016/j.gloenvcha.2011.01.017

[40] Zhang, X., Shen, G.Q.P., Feng, J. \& Wu, Y., Delivering a low-carbon community in China: technology vs. strategy? Habitat International, 37(1), pp. 130-137, 2013. https://doi.org/10.1016/j.habitatint.2011.12.010

[41] Larsson, A., Azar, C., Sterner, T., Strömberg, D. \& Andersson, B., Technology and policy for sustainable development. Paper prepared for the European Commission by a team from the Centre for Environment and Sustainability, Göteborg, Sweden, 2002.

[42] Onea, D., Urban community - an approach to spatial context. Geopolitics History \& International Relations, 5, 2012.

[43] Bye, B., Fæhn, T. \& Rosnes, O., Residental energy efficiency and European carbon policies: a CGE-analysis with bottom-up information on energy efficiency technologies (Discussion Papers No. 817). Statistics Norway, 2015.

[44] Bing, J., Sun, Z. \& Liu, M., China's energy development strategy under the low-carbon economy. Energy, 35(11), pp. 4257-4264, 2010. https://doi.org/10.1016/j.energy.2009.12.040 
[45] Chance, T., Towards sustainable residential communities: the Beddington Zero Energy Development (BedZED) and beyond. Environment and Urbanization, 21(2), pp. 527544, 2009. https://doi.org/10.1177/0956247809339007

[46] Sun, C.G. \& Zhang, Z.Q., Analysis on current situation and influence factors of community residents' participation during the process of low-carbon city construction - on the basis of an empirical investigation in Chengyang district, Qingdao, Mainland China. Journal of Urbanology, 6(1), pp. 29-62, 2015.

[47] Liu, Z., Yu, J. \& Zhang, D., Study on low-carbon building ecological city construction in Harmonious Beibu Gulf culture. Procedia Environmental Sciences, 10, pp. 18811886, 2011.

https://doi.org/10.1016/j.proenv.2011.09.294

[48] Fudge, S., The persistent challenge of encouraging public participation in the low-carbon transition. Carbon Management, 4(4), pp. 373-375, 2013.

https://doi.org/10.4155/cmt.13.32

[49] Hodson, M., Marvin, S. \& Bulkeley, H., The intermediary organisation of low carbon cities: a comparative analysis of transitions in Greater London and Greater Manchester. Urban Studies, 50(7), pp. 1403-1422, 2013. https://doi.org/10.1177/0042098013480967

[50] Banister, D., The sustainable mobility paradigm. Transport Policy, 15(2), pp. 73-80, 2008. https://doi.org/10.1016/j.tranpol.2007.10.005

[51] Russo, R. \& Boutueil, V., Toward low carbon mobility: Tackling road transport emissions. Les Cahiers de la Chaire Economie du Climat - information and debates series, 2011.

[52] Prabhu, A. \& Pai, M., Buses as Low-carbon mobility solutions for urban India. Transportation Research Record Journal of the Transportation Research Board, 2317, pp. 15-23, 2012. https://doi.org/10.3141/2317-03

[53] Salonen, M., Broberg, A., Kyttä, M. \& Toivonen, T., Do suburban residents prefer the fastest or low-carbon travel modes? Combining public participation GIS and multimodal travel time analysis for daily mobility research. Applied Geography, 53, pp. 438-448, 2014. https://doi.org/10.1016/j.apgeog.2014.06.028

[54] Mendoza, J.M.F, Sanyé-Mengual, E., Angrill, S., García-Lozano, R., Feijoo, G., Josa, A. \& Gabarrell, X., Development of urban solar infrastructure to support low-carbon mobility. Energy Policy, 85(85), pp. 102-114, 2015. https://doi.org/10.1016/j.enpol.2015.05.022

[55] Philp, M. \& Taylor, M.A.P., A research agenda for low carbon mobility: issues for 'new world' cities. International Journal of Sustainable Transportation, 11(1), pp. 49-58, 2017. https://doi.org/10.1080/15568318.2015.1106261

[56] Nakamura, K. \& Hayashi, Y., Strategies and instruments for low carbon urban transport: an international review on trends and effects. Transport Policy, 29, pp. 264-274, 2013. https://doi.org/10.1016/j.tranpol.2012.07.003

[57] Zhang, Y.P., Low-carbon economy and low-carbon life. Sino-Global Energy, 14(4), pp. 12-15, 2009. 
[58] Carvajal, L., Exploring the relationship between neighborhood social interactions and urban sprawl in U.S. metropolitan regions. University of Massachusetts Amherst, Amherst, MA 2011.

[59] Abdulhamid, G. \& Marzieh, J., An investigation of the effective factors in enhancing residents' social interaction in residential districts (case study: Darakeh neighborhood in Tehran). Iranian Architecture and Urbanism, 7, pp. 57-64, 2014.

[60] Abbaszadeh, S., Reinforcing social interaction among Persian neighborhood communities in new high-rise residential development. Universiti Putra Malaysia, 2009.

[61] Zhang, Y. \& Wang, J., Low-carbon green space construction in urban communities. Nature Environment \& Pollution Technology, 13(3), pp. 571-576, 2014.

[62] Vaccari, F.P., Gioli, B., Toscano, P. \& Perrone, C., Carbon dioxide balance assessment of the city of Florence (Italy), and implications for urban planning. Landscape \& Urban Planning, 120(6), pp. 138-146, 2013. https://doi.org/10.1016/j.landurbplan.2013.08.004

[63] Moulay, A., Ujang, N. \& Said, I., Legibility of neighborhood parks as a predicator for enhanced social interaction towards social sustainability. Cities, 61(2017), pp. 58-64, 2017. https://doi.org/10.1016/j.cities.2016.11.007

[64] Adedeji, Y.M.D, Aluko, O.O. \& Ogunsote, O.O., Sustainable landscaping and green housing in tropical climates: a case study of Akure, Nigeria. Proceedings of the 1st International Conference on Man, Technological Advancement and Sustainable Environment held at the Federal University of Technology, Akure, pp. 204-213, 2010.

[65] Haywood, S., An empowerment model for building neighborhood community. Journal of Progressive Human Services, 7(2), pp. 63-76, 1996.

[66] Bonds, M. \& Farmer-Hinton, R.L., Empowering neighborhoods via increased citizen participation or a Trojan Horse from city hall: the neighborhood strategic planning (NSP) process in Milwaukee, Wisconsin. Journal of African American Studies, 13(1), pp. 74-89, 2009.

https://doi.org/10.1007/s12111-008-9071-4

[67] Chambers, R., Whose reality counts?: putting the first last. London: Intermediate Technology Publications Ltd (ITP), 1997.

[68] Seymoar, N.K., Ballantyne, E. \& Pearson, C.J., Empowering residents and improving governance in low income communities through urban greening. International Journal of Agricultural Sustainability, 8(1-2), pp. 26-39, 2010.

https://doi.org/10.3763/ijas.2009.0467

[69] Liang, Y. \& Cao, Y., The policy system innovation for the development of low-carbon economy in China. International Conference on Future Information Technology and Management Engineering. IEEE, pp. 52-55, 2010.

[70] Alam, A., Ghafghazi, G. \& Hatzopoulou, M., Traffic emissions and air quality near roads in dense urban neighborhood. Transportation Research Record Journal of the Transportation Research Board, 2427, 83-92, 2014.

https://doi.org/10.3141/2427-09

[71] Murota, M., Role of community-based approaches with administrative support in an urban low-carbon society in the UK. Journal of Asian Architecture \& Building Engineering, 13(3), pp. 593-600, 2014.

https://doi.org/10.3130/jaabe.13.593 
[72] Ratliff, K.A, Howell, J.L. \& Redford, L., Attitudes toward the prototypical environmentalist predict environmentally-friendly behavior. Journal of Environmental Psychology, 51, pp. 132-140, 2017.

https://doi.org/10.1016/j.jenvp.2017.03.009

[73] Li, Q. \& Dai, Y.C., Research on government participation mechanism of international environmental cooperation in low carbon model. China Population, Resources and Environment, 20(10), pp. 68-71, 2010.

[74] Li, H.Y., Creating a low carbon life style in developed countries and its enlightenment to China - based on UK and Denmark. Journal of Hunan University of Commerce, 21(3), pp. 26-31, 2014. 